\title{
DETERMINAÇÃO DA FRAGILIDADE AMBIENTAL POR MAPEAMENTO NO MUNICÍPIO DE DOUTOR CAMARGO-PR.
}

Felipe Pacheco Spirlandelli - felipe.pacheco02@ hotmail.com

Universidade Tecnológica Federal do Paraná

Érico Borges Fernandes - ericobfernandes@gmail.com

Universidade Tecnológica Federal do Paraná

José Hilário Delconte Ferreira - jhferreira@utfpr.edu.br

Universidade Tecnológica Federal do Paraná 


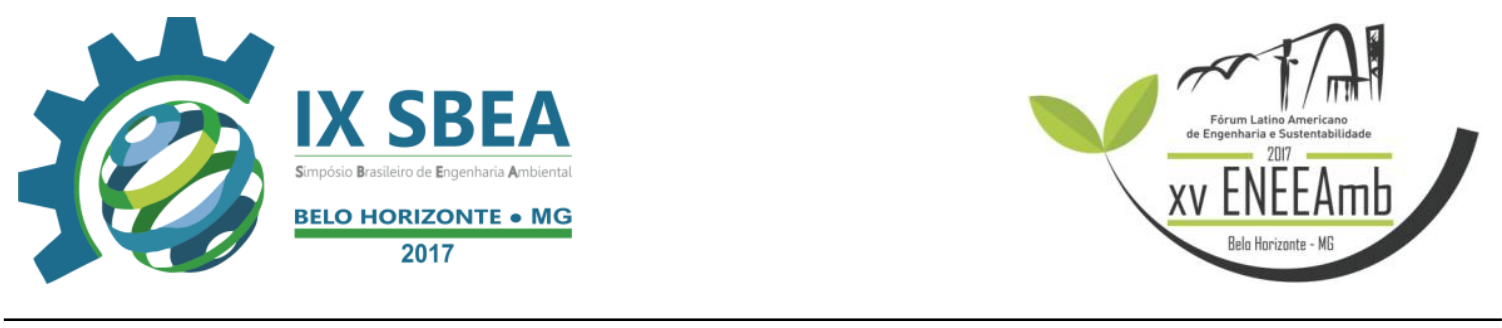

\section{RESUMO}

O geoprocessamento seria um dos meios, no qual auxiliaria, em um futuro projeto, nas alterações que ocorrem na paisagem, uma avaliação do potencial dos recursos naturais, um planejamento aplicado na gestão ambiental buscando amenizar influências antrópicas em dado local e espaço, entre outras particularidades. $\mathrm{O}$ trabalho tem como objetivo evidênciar os parametros importantes como Declividade e Uso da Terra, para determinação da fragilidade ambiental do município de Doutor CamargoPR, usando o auxílio de softwares e ferramentas digitais, como o SPRING 5.4.2 (Sistema de Processamento de Informações Georreferenciadas) e o Qgis 2.14.12, gerando mapas temáticos, nos quais poderá se interpretar a relação desses parâmetros com suscetibilidade do local. Com a imagem Bing, do município, a mesma se dividi em outras 4 imagens seguindo respectivamente as seguintes datas: Julho de 2010, Setembro de 2011, Abril de 2012 e Maio de 2011, aplicado a um zoom de 19.

Palavras-chave: Suscetibilidade ambiental, Spring, Qgis, Uso da Terra.

\section{OBJETIVO}

Estudos atuais de impactos ambientais vem mostrar, que as ações antrópicas tem uma grande responsabilidade para o prejuízo e degradação de regiões e áreas exploradas (SOUZA, 2012). Existem atualmente meios que podem dimensionar parametros de extrema relevância nas definições de fragilidade ambiental de locais suscetivéis a impactos sendo esses naturais ou não.

De acordo Santos et al. (2007), o geoprocessamento seria um dos meios, no qual auxiliaria, em um futuro projeto, nas alterações que ocorrem na paisagem, uma avaliação do potencial dos recursos naturais, um planejamento aplicado na gestão ambiental buscando amenizar influências antrópicas em dado local e espaço, entre outras particularidades.

O trabalho tem como objetivo evidênciar os parametros importantes como Declividade e Uso da Terra, para determinação da fragilidade ambiental do município de Doutor Camargo-PR, usando o auxílio de softwares e ferramentas digitais, como o SPRING 5.4.2 (Sistema de Processamento de Informações Georreferenciadas) e o Qgis 


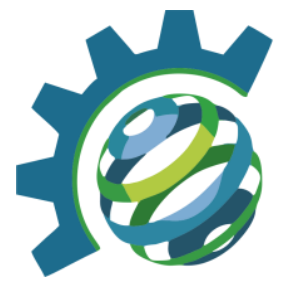

2.14.12, gerando mapas temáticos, nos quais poderá se interpretar a relação desses parâmetros com suscetibilidade do local.

\section{METODOLOGIA}

A área de estudo sendo do município de Doutor Camargo-PR, localizado no estado do Paraná, na Mesorregião Geográfica Norte Central Paranaense e Microrregião Geográfica Floraí (IPARDES, 2016), Figura 1.

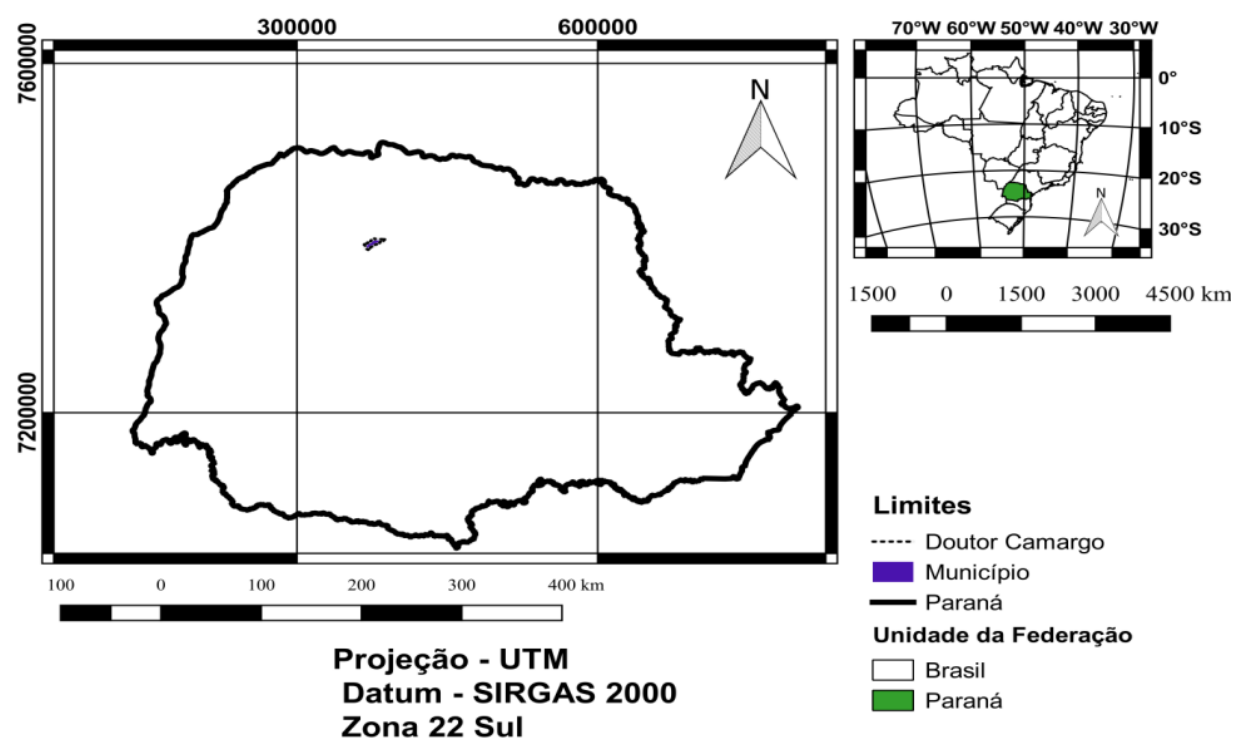

Figura 1: Localização de Doutor Camargo no estado do Paraná.

O trabalho presente utilizou-se de ferramentas digitais sendo softwares específicos para sua realização. Utilizando o Laboratório de Geoprocessamento, da Universidade Tecnológica Federal do Paraná - Câmpus Campo Mourão, buscou-se imagem Bing do local em estudo e com o auxílio do software Spring fez as devidas edições comentadas abaixo.

Com a imagem Bing, do município, a mesma se dividi em outras 4 imagens seguindo respectivamente as seguintes datas: Julho de 2010, Setembro de 2011, Abril de 2012 e Maio de 2011, aplicado a um zoom de 19. Originalmente a imagem tinha a resolução espacial de $\mathrm{X}=0,542522$ e $\mathrm{Y}=0,598576$, já para o Spring, para facilitar o 
processamento digital da imagem, esta resolução foi reamostrada para $X=2,71261$ e para $\mathrm{Y}=2,99288$.

Dados socioeconomicos analisados, por meio das informações fornecidas por Ipardes (2016), pode-se determinar a identificação das classes de uso da terra do município. De acordo com o Manual Técnico de Uso da Terra (IBGE, 2013), utilizou-se o Spring para realizar a classificação semiautomática das categorias de classes temáticas, definidas a seguir. No QGis, seguindo o Manual Técnico do Uso da Terra, ocorreu a classificação, através da vetorização, com o auxílio das imagens de satélite do Google Earth, coletou-se amostras dessas classes temáticas em todo o município e assim com as outras classes criadas, seguindo sempre o que município dispunha. Feita as coletas de amostras, no Spring recebe-se os dados vetoriais que será convertidos em dados matriciais.

A declividade é um dos parâmetros essêncial para o trabalho, utilizando dados SRTM, obtidos pelo Earth Explorer, e em seguida criando-se classes temáticas para este parâmetro, de acordo com os dados de cada perfil a se trabalhar, classificou-se em cores padronizadas suas informações. A Declividade das classes temáticas foram definidas segundo a Embrapa (1999), classes essas sendo: Plano de 0 - 3\%, Suave ondulado de 3 $-8 \%$, de $8-20 \%$ Ondulado, de $20-45 \%$ Forte ondulado, de $45-75 \%$ Montanhoso e $>75 \%$ Escarpado.

No mesmo programa Spring trabalhou-se com a Fragilidade ambiental criando um algoritmo no qual executa a Linguagem Legal (Linguagem espacial para Geoprocessamento algébrico), cujo cruza informações desses parâmetros somada ao clima determinaram a fragilidade do município em questão, sendo analisados e classificados atribuindo pesos que variam de 1 a 5 , o peso 1 com menor fragilidade e o peso 5 sendo máxima fragilidade.

Segundo Franco et al., (2012), regiões com declividade Plano designa uma Fragilidade com peso 1, Suave ondulado peso 2, peso 3 para Ondulado, peso 4 Montanhoso e peso 5 Escarpado ( Altamente montanhoso). De acordo com Souza et al., (2011), trazendo a idéia de fragilidade para áreas Florestais e corpos d'agua cabendo peso 1, para vegetação secundária, Campestre, Capoeira peso 2, peso 3 para Culitvo 
permanente e Silvicultura, peso 4 para áreas de Cultivo temporário e Pastagem e peso 5 para Áreas Urbanas e Estrutura rural.

Conforme Mass e Ross (2012) correlaciona a Fragilidade com a precipitação pluviométrica. No parâmetro Clima foi fundamental a junção das informações de Uso da Terra e de Declividade para sua determinação, em Doutor Camargo existe a influência de um único Clima sendo esse Temperado, ou subtropical, úmido com verão quente (Cfa), seguindo classificação Köeppen, analisando as informações pode-se chegar a uma classificação com peso 2 de Fragilidade ambiental, indicando Baixa Fragilidade.

Executou-se o Programa LEGAL, uma categoria temática foi criada para a Fragilidade, com as suas devidas classes temáticas, variando de Muito Baixa com Peso 1, Baixa com peso 2, peso 3 para Intermediária, peso 4 Alta e peso 5 para Muito alta.

\section{RESULTADOS E DISCUSSÃO}

A Tabela 1, destaca as atividades econômicas predominantes no município de Doutor Camargo-PR, os seus estabelecimentos e suas áreas de abrangência medidas em hectares (IBGE, 2006). A cultura temporária se mostra com superioridade em relação as outras atividades econômicas, demonstrando a agricultura como base da renda do município.

Tabela 1: Estabelecimentos Agropecuários e área segundo as atividades econômicas 2006.

\begin{tabular}{|l|c|c|}
\hline \multicolumn{1}{|c|}{ ATIVIDADES ECONÔMICAS } & ESTABELECIMENTOS & ÁREA (ha) \\
\hline Lavoura temporária & 480 & 9.322 \\
\hline Horticultura e floricultura & 4 & 13 \\
\hline Lavoura permanente & 31 & 150 \\
\hline $\begin{array}{l}\text { Produção de sementes, mudas e outras formas de } \\
\text { propagação vegetal. }\end{array}$ & 1 & $\mathrm{X}$ \\
\hline Pecuária e criação de outros animais & 73 & 839 \\
\hline Produção florestal de florestas plantadas & 1 & $\mathrm{X}$ \\
\hline Produção florestal de florestas nativas & - & - \\
\hline Pesca & - & - \\
\hline Aquicultura & - & - \\
\hline
\end{tabular}




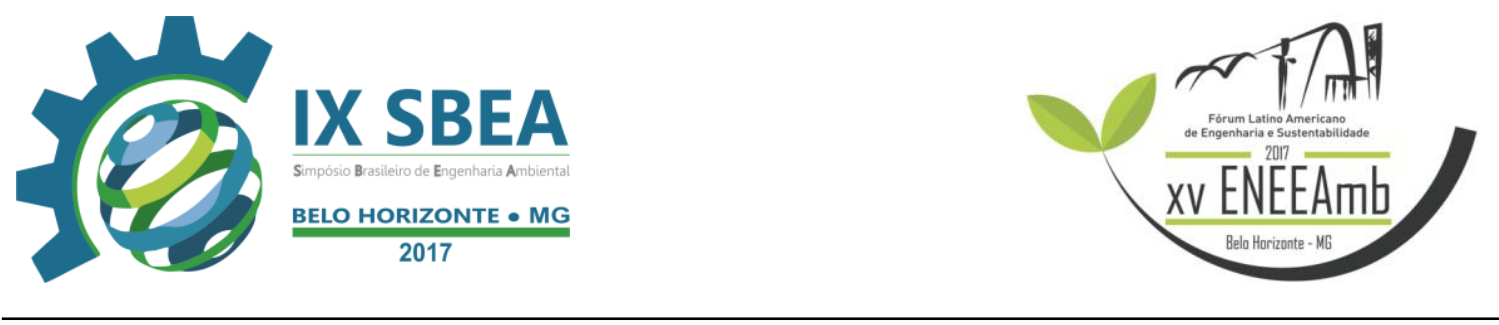

TOTAL 590 10.346

Fonte: IBGE - Censo Agropecuário.

Por meio de imagens de satélite observou-se a ocupação e o uso da terra do município de Doutor Camargo-PR, seguindo o Manual Técnico de Uso do Solo (IBGE, 2013). A Figura 2 e os dados da Tabela 2, mostram a distribuição das classes de uso da terra e as áreas que cada classe ocupa no município. Como se apresenta, a maior área é a de Cultura Temporária chegando a 92, $2859 \mathrm{~km}^{2}$ no município, evidênciando assim a ação antrópica no local, buscando desmatar para que possam fazer práticas de cultivos, trazendo com isso inúmeros problemas não apenas para o solo, como também para o ambiente. Os locais com pastagem correspondem há 9,057 km² da área do município, ocorrendo maior fragilidade ambiental neste locais, sendo influência da grande exposição do solo em conjunto com uma declividade acentuada nestes locais, já a classe florestal abrange 9,151412 $\mathrm{km}^{2}$ da área do município, registrando-se com índices de Fragilidade muito baixa, devido ter caracteristiscas como grande proteção do solo e presença de vegetação de grande porte quem tem influência na diversidade do local. Os resultados demonstram maior predominância das classes: Suave ondulado e Ondulado, no município há uma menor influência das classes Forte Ondulado e Montanhoso, evidênciando uma grande área plana, fator este que favorece o incentivo de culturas (Figura 3).

Tabela 2: As classes de Uso do Solo e suas respectivas áreas em $\mathrm{km}^{2}$.

\begin{tabular}{|l|c|}
\hline \multicolumn{1}{|c|}{ Classes de Uso do Solo } & Área $\mathbf{( k m}^{\mathbf{2}} \mathbf{)}$ \\
\hline Psicultura & 0,135345 \\
\hline Cultura Temporária & 92,2859 \\
\hline Cultura Permanente & 0,7766 \\
\hline Pastagem & 9,0570 \\
\hline Sivilcutura & 0,159044 \\
\hline Estrutura Rural & 0,3131809 \\
\hline Florestal & 9,151412 \\
\hline Campestre & 3,26952 \\
\hline Corpos d'água & 1,445925 \\
\hline
\end{tabular}

Fonte: Dados obtidos do aplicativo Spring 5 


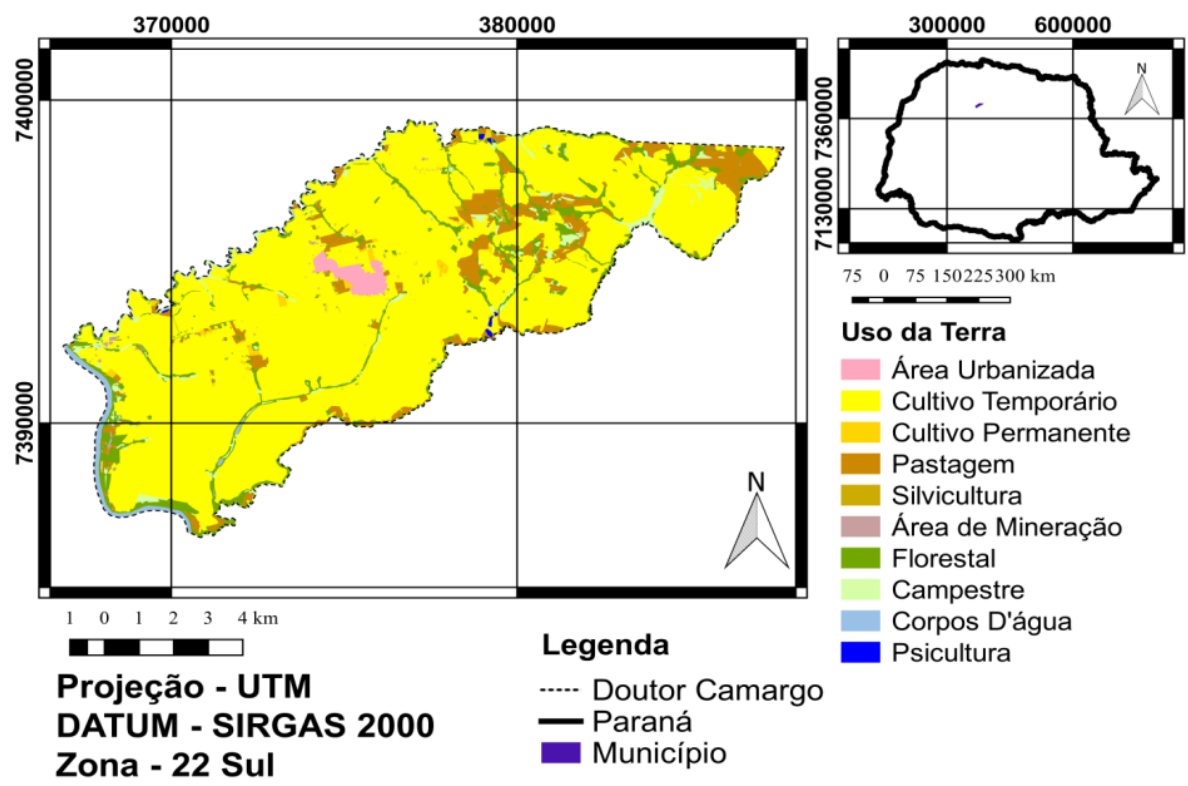

Figura 2: Classes de Uso da Terra presentes no muncípio.

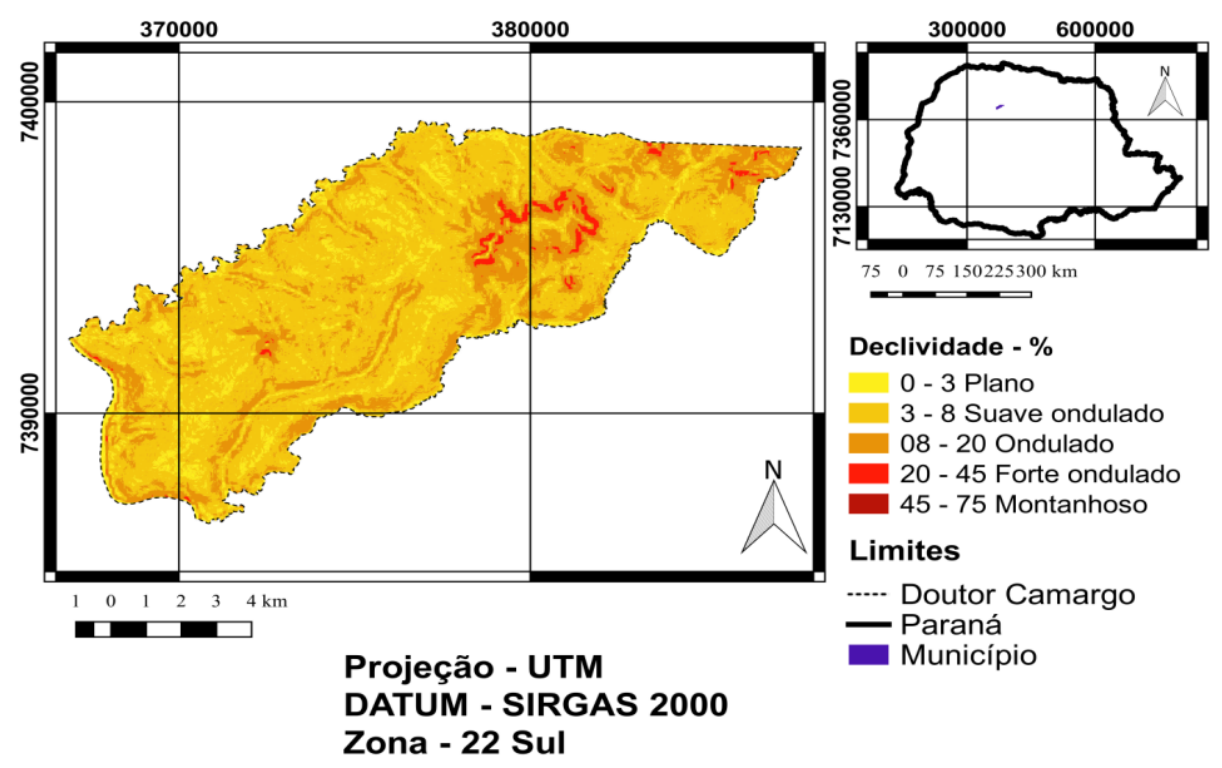

Figura 3: Declividade de Doutor Camargo no estado do Paraná.

Após a caracterização da Fragilidade Ambiental do município Doutor Camargo - PR, por meio do Programa Legal inserido no software Spring, no qual relacionou os fatores de Uso da terra e Declividade, obtendo uma classificação de fragilidade com 


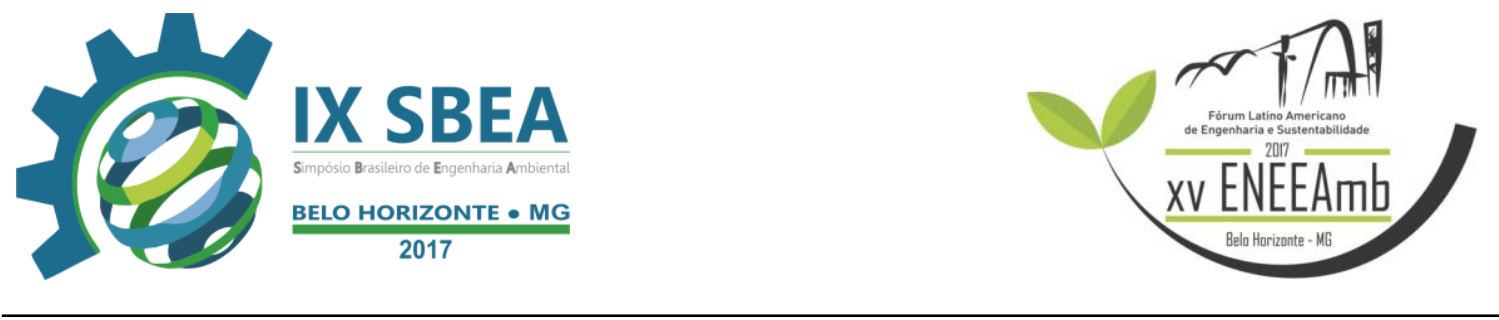

níveis variando entre Baixo, Intermediário e Alto (Figura 4). Na tabela 3 apresenta-se a abrangência em área dos determinados níveis de fragilidade no local.

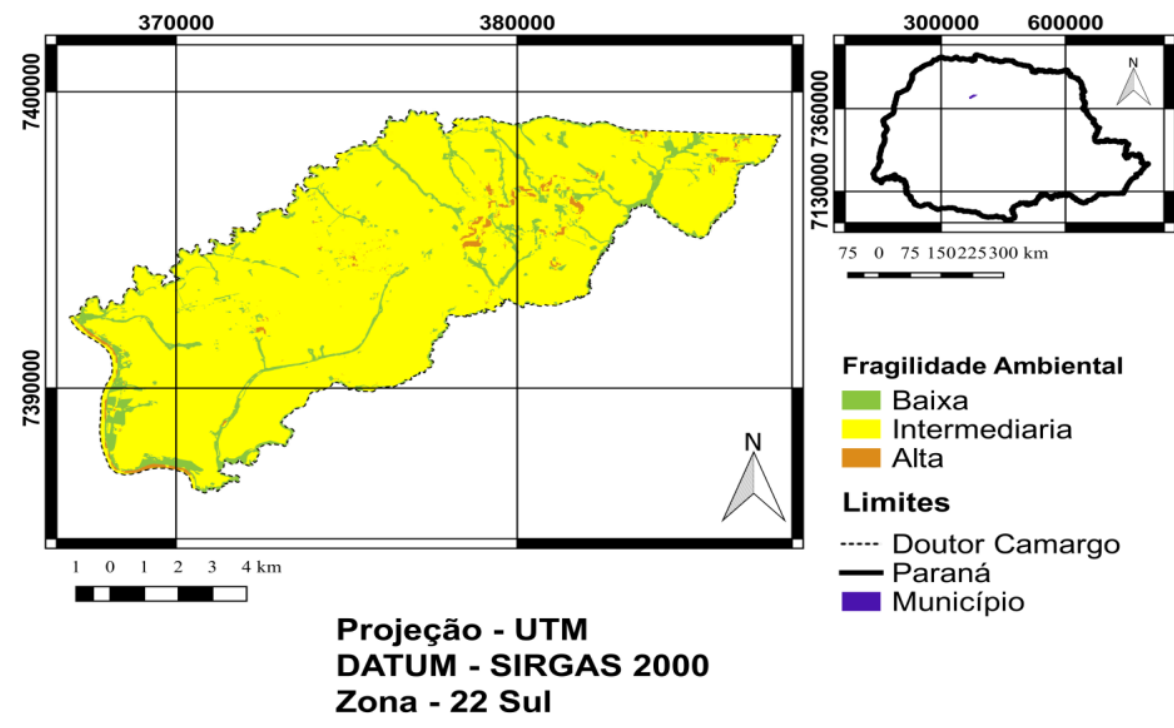

Figura 4: Fragilidade Ambiental de Doutor Camargo no estado do Paraná.

Tabela 3: Classes de Fragilidade Ambiental correspondentes no município de Doutor Camargo - PR.

\begin{tabular}{|l|l|}
\hline Classes Fragilidade Ambiental & Área $\mathbf{( k m}^{\mathbf{2}} \mathbf{)}$ \\
\hline Baixa & 10,899809 \\
\hline Intermediária & 105,42756 \\
\hline Alta & 1,6725 \\
\hline
\end{tabular}

Fonte: Dados obtidos no aplicativo Spring 5.4.2.

Em locais com relevo variando de Ondulado a Montanhoso se encontra a presença de pastagem, tendo como base a criação de animais em terras que se tem menor incentivo para aplicação de culturas, a união dessas duas situações citada anteriomente tem ação direta na suscetibilidade do local, evidênciado através do nível alto de fragilidade encontrado, situação que tem como gerador as ações bióticas e antrópicas, sabe-se que locais com relevo acentuado se mostra ser mais propícios a ter maior fragilidade devido ao sua exposição ação biótica fator também observado por Donha, Souza e Sugamosto (2006) em seus estudos. 


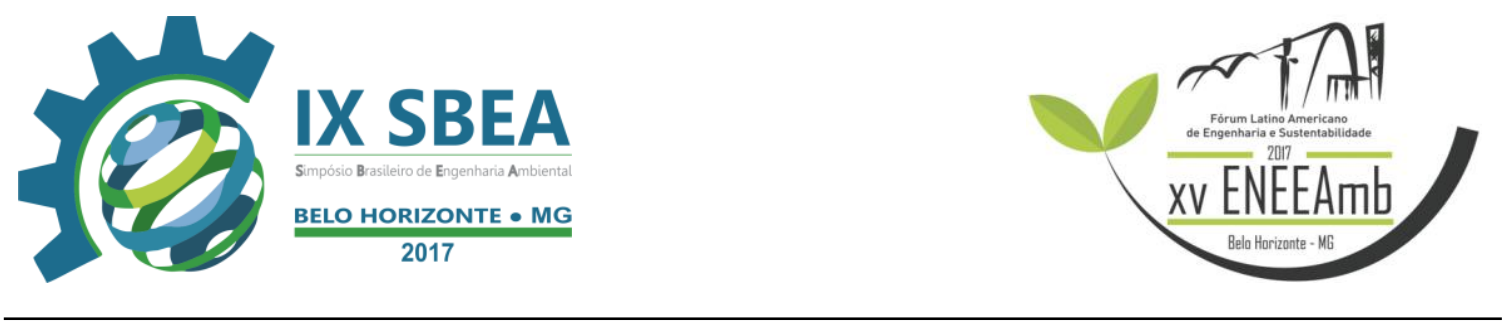

A cultura temporária, locais que tem como característica a grande rotação de cultura e exploração intensa do solo, nos quais tendem a apresentar maiores níveis de Fragilidade Ambiental, situação esta que não se concretizou, pois observou-se uma fragilidade intermediaria no local, resultados similares aos encontrados por Fushita et. al. (2010) na sua pesquisa. O relevo plano para essas áreas, pode ser um parâmetro no qual justifica a intensidade intermediária da fragilidade ambiental.

Medidas mitigadoras podem ser aplicadas diretamente no parâmetro de Uso da Terra, buscando em regiões de Pastagem com alta suscetibilidade a erosões, uma melhor distribuição dos animais criados, reduzindo a compactação e consequentemente o escoamento superficial no solo, diminuindo os desgastes de solos e terrenos, como a divisão de quadrantes no terreno, para a rotatividade dos animais criados, em intervalos de tempo determinados, assim tendo tempo para que o solo usado se recupere, não fique prejudicado demais.

Com relação aos fragmentos florestais encontrados em Doutor Camargo-PR, pode-se observar que a fragilidade ambiental se enquadra em um nível baixo, situação devido uma proteção do solo mais intensa existentes nesses locais, tendo como consequência a diminuição dos efeitos erosivos, preservação da biodiversidade e conservação de ecossistemas presentes no meio (BRASIL-MMA, 2002). Estes locais possuem uma área inferior a $10 \%$ da área total do munícipio, evidênciando o avanço descontrolado do crescimento urbano, juntamente com as práticas de culturas agrícolas, aplicações pecuárias e desmatamento.

\section{CONCLUSÕES/RECOMENDAÇÕES}

Medidas mitigadoras para amenizar determinados impactos que agravam a fragilidade do município, seria aplicações diretas no parâmetro de Uso da Terra, buscando em regiões de Pastagem com alta suscetibilidade a erosões uma melhor distribuição dos animais criados, reduzindo a compactação e consequentemente o escoamento superficial no solo, diminuindo os desgastes de solos e terrenos, como a divisão em quadrantes no terreno para a rotatividade dos animais criados, em intervalos de tempo determinados, assim tendo tempo para que o solo usado se recupere, não fique prejudicado demais. 


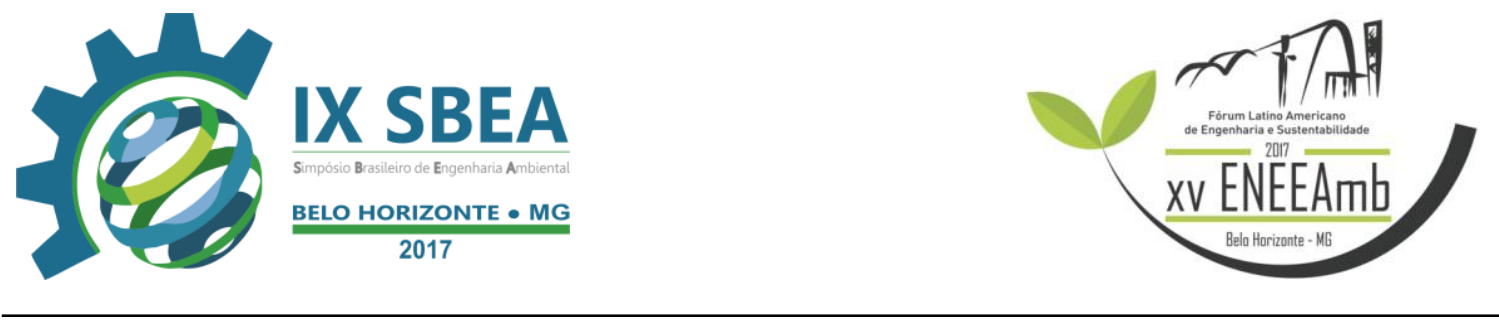

No Cultivo Temporário, pode-se elaborar, planejamento no uso e conservação do solo, uma delas seria a rotatividade de culturas distintas, evitando o uso de maquinários, propondo fazer um plantio direto ao invés do plantio convencional.

\section{REFERÊNCIAS BIBLIOGRÁFICAS}

BRASIL-MMA. . Resolução CONAMA 303, de 20 de março de 2002. 2002. Disponível em: <http://www.mma.gov.br/port/conama/legiabre.cfm?codlegi=299>. Acesso em: 25 maio 2017.

DONHA, Annelissa G.; SOUZA, Luiz C. de P.; SUGAMOSTO, Maria L.. Determinação da fragilidade ambiental utilizando técnicas de suporte à decisão e SIG. Revista Brasileira de Engenharia Agrícola e Ambiental, Campina Grande, Pb, v. 10, n. 1, p.175-181, 2006. Anual.

EMBRAPA. Centro Ncaional de Pesquisa de Solos. Sistema Brasileiro de Classificação de Solos. Rio de Janeiro, 1999. 412 p.

FRANCO, G. B. et al. Relação Qualidade da água e fragilidade a ambiental da Bacia do Rio Almada, Bahia. Revista Brasileira de Geociências, Bahia, v. 42, p. 114-127, ago./out. 2012.

IPARDES. Caderno estátistico do município de Doutor Camargo. 2016. Disponível em:

http://www.ipardes.gov.br/cadernos/MontaCadPdf1.php?Municipio=87155\&btOk=ok. Acesso em: 24 de abr. 2017.

IBGE. Manuais Técnicos em Geociências. Rio de Janeiro 2013. Disponível em: http://biblioteca.ibge.gov.br/visualizacao/livros/liv81615.pdf. Acesso em 24 de abr. 2017.

MASSA, E. M.; ROSS, J. L. S. Aplicação de um modelo de fragilidade ambiental relevo-solo na Serra da Camtareira, bacia do Córrego do Bispo, são Paulo-SP.. Revista do Departamento de geografia - USP, São Paulo - SP, v. 24, p. 57-59, ago./set. 2012.

SANTOS, L. J. C.; OKA-FIORI, C.; CANALLI, N. E.; FIORI, A. P.; SILVEIRA, C. T.; SILVA, J. M. F.; Mapeamento da vulnerabilidade geoambiental do estado do Paraná. Revista Brasileira de Geociências. Ano 37. n.4, p.812-820, 2007.

SOUZA, M.M.; COSTA, L.H.; CARVALHO, D. A. S. Utilização de ferramentas de geoprocessamento para mapear as fragilidades ambientais na área de influência direta da UHE de Belo Monte, Pará. Espaço Plural. Belo Monte. Ano XII. N ${ }^{\circ} 25.2^{\circ}$ Semestre 2012. ISSN1518-4196 